\title{
Nitrogen-rich Porous Carbon Derived from Biomass as High Performance Electrode Materials for Supercapacitors
}

\author{
JianQiang Zhang ", SenYang Song, JieChen Xue, Ping Li, ZhiShang Gao, YanBo Li, \\ Zheng Zhang, HuiXia Feng and HeMing Luo \\ College of Petrochemical Technology, Lanzhou University of Technology, Lanzhou 730050, PR \\ China. \\ "E-mail: zhangjq@lut.cn, luohm666@163.com
}

doi: $10.20964 / 2018.06 .09$

Received: 31 December 2017 / Accepted: 24 February 2018 / Published: 10 May 2018

\begin{abstract}
In situ nitrogen doped porous carbon materials (NC) has been architectured vis hydrothermal carbonization coupling method by the nitrogen-rich biomass, black garlic (BG). The resulting NC performs a high specific surface area, above $2000 \mathrm{~m}^{2} \mathrm{~g}^{-1}$ with abundant mesoporous and microporous hierarchical structure, as well as a high graphitization degree demonstrated by XRD and Raman. Further electrochemical measurements revealed that the corresponding electrode prepared by these NC can lead to a significantly high specific capacitance of $331 \mathrm{~F} \mathrm{~g}^{-1}$ in a $6 \mathrm{M} \mathrm{KOH}$ aqueous electrolyte, which is higher than other porous carbon materials obtained by most biomass. Furthermore, the corresponding electrode shows a high degree of cycling stability. This contribution shows that the NC derived from nitrogen-rich biomass are more environmental-friendly and less energy consuming than that of nitrogen doped carbon materials obtained from other conventional methods. Also, the effect of hydrothermal treatment has been discussed relative to the conventional one-step carbonization.
\end{abstract}

Keywords: In situ doped, nitrogen doped, porous carbons, black garlic, supercapacitors

\section{$\underline{\text { FULL TEXT }}$}

(C) 2018 The Authors. Published by ESG (www.electrochemsci.org). This article is an open access article distributed under the terms and conditions of the Creative Commons Attribution license (http://creativecommons.org/licenses/by/4.0/). 